\title{
ACERCA DEL CONCEPTO DE POESIA EN LEZAMA LIMA
}

\author{
POR \\ EDUARDO URDANIVIA BERTARELLI \\ Universidad de Lima, Perú
}

\section{LEZAMA Y LA POESIA}

Alguna vez Lezama Lima expresó que "uno no se dedica a la poesía. La poesía es algo más misterioso que una dedicación" ${ }^{\text {"1. }}$ Con estas palabras, el poeta cubano planteaba ya una categoría medular en su obra y un rasgo substancial en su trabajo poético: la vida como totalidad abarcadora. En verdad Lezama no se refería a la poesía como un oficio exterior a sí mismo del cual podía tomarse distancia; todo lo contrario, la poesía es concebida como parte integrante de la existencia del poeta; éste no se "dedica" a ella, sino que la encarna en sí mismo, y no es una tarea que se ejerza - como podria ejercerse cualquier profesiónsino algo más misterioso que toma cuerpo y se transubstancia en la vida y en las palabras del poeta.

En la misma línea de totalidad vital, el binomio que opone presencia y ausencia es un componente clave en la teoría poética de Lezama; la "presencia de la imagen" (p. 12) contrapuesta al "latido de la ausencia" (p. 12); ésta hace referencia al vacío, a la alucinación, al no ser; aquélla apunta a la materia, al reto que significa para el ser humano la existencia de lo concreto, a esa "cantidad hechizada" (p. 16) y desconocida.

Entre estas ausencia y presencia respecto a lo exterior al poeta, así como a su propio mundo interior, vuelve a encontrarse la totalidad del ser, y se desenvuelve la poesía no como oficio, sino como manera de existir. La poesía es tan radical en ese su abarcar toda la vida, que involucra en ella lo que es y lo que no es, el ser y el no ser que sólo "la te" en una ausencia que, paradójicamente, se deja sentir.

Un tercer elemento es la soledad. Lezama se au todefinió como un solitario: "he sido un solitario ... soy un solitario ... seguiré siendo un solitario"(p. 14). Esta condición no amaina con la compañía, sino que se robustece, porque la totalidad

\footnotetext{
1"Interrogando a Lezama", José Lezama Lima. Serie Valoración Múltiple. (La Habana: Casa de las Américas, 1970) 11. De aquí en adelante, salvo expresa aclaración lodas las citas se refieren a este texto.
} 
misteriosa que es la poesia sólo se manifiesta en la soledad; ésta, más que aislamiento - o además-, es un estado interior, una disposición del espíritu, una presencia irrenunciable e imprevista, una vocación.

De lo dicho se infiere que entre el poeta, la poesía y el poema existen nexos de mutua implicancia, y aunque sea posible distinguir entre ellos, no puede pensarse en uno sin los otros. Esto es lo que Lezama llamó la "hipóstasis de la poesía" (p. 16), con una palabra tomada sin duda de la teología cristiana y que hace referencia a la consubstancialidad de Dios Padre, Dios Hijo y Dios Espíritu Santo; es decir, que los tres comparten una única y la misma naturaleza en una unión hipostática. Así, la trilogía poeta-poesía-poema se constituye en una especie de "trinidad" en la que pueden distinguirse tres realidades distintas y una sola y verdadera esencia. Para acercarse a la poesia, ha dicho Lezama, es necesario hablar de ella, de quien la crea, y del producto de la creación. La poesía es la convergencia de esos tres elementos, el fuego producido por el encuentro de "lo estelar que desciende y lo telúrico que se evapora" (p. 27).

El ejercicio de la poesia, dentro de este concepto trinitario y por ser un acto esencialmente creador, convierte al poeta en dador de vida y, por tanto, en vencedor de la muerte. Esto es importante para entender a Lezama como un poeta vital que, a pesar de la soledad que postula como meollo de su existencia, es por sobre todo un creador de vida y esperanza. No significa esto que Lezama niegue la muerte como fenómeno ineludible y último de la existencia humana; por el contrario, pocos comoél han sido tan hondamente marcados por la muerte, a causa del temprano fallecimiento de su padre, hecho ante el cual se alza la omnipresencia de su madre incluso después de la desaparición física de ésta. Estas dos figuras explican, tal vez, el origen de esa presencia/ausencia de la que hemos hablado. Pero Lezama acentúa la resurrección más que el morir; todo poeta, ha dicho, "entona ante la muerte un hurra victorioso" (p. 27); el hombre no es un ser para la muerte sino un ser para la vida; el poeta propicia la resurrección, y puede exclamar "iAdónde está, muerte, tu victoria!", que es el grito de la liturgia cristiana del Domingo de Pascua.

$\mathrm{El}$ origen cristiano de estos conceptos es evidente, y no sólo por concebir de modo trinitario a la poesía, sino también al pensar en sus elementos unidos hipostáticamente, transubstanciados y entretejiéndose los unos con los otros. No es sólo la muerte lo que es medular en la figura de Cristo, sino su resurrección, su triunfo sobre la muerte, al punto de que si no hubiese resucitado nuestra fe no tendría ningún sentido ${ }^{2}$. Oponiendo esta idea paulina a la visión de Heidegger del ser para la muerte, Lezama puede decir que el poeta es inmortal, que sobrevive a la muerte con su vida - que es su obra-, y con su obra - que es también su vida.

Las consecuencias de esta visión son múltiples. Dios es el dador de vida por excelencia; el hombre es creado a su imagen y semejanza y por lo tanto su misión

${ }^{2}$ I Corintios 15,14 y ss. 
primera es dar vida y ser siempre signo de ella. El cuerpo humano "es la más hermosa de las formas logradas" y la cópula "es el más apasionado de los diálogos" (p. 24). La vida prevalece así sobre la muerte.

El sistema poético de Lezama Lima se fue gestando en forma paulatina y fue plasmado ya en la madurez del poeta, cuando éste se encontró con que la poesía "bullia, hervia, como afanosa de quererse convertir en otro mundo" ( $\mathrm{p}$. 21). No es un sistema que pretenda aclarar las cosas para los demás o aportar a la teoria poética; simplemente está, es, "respira" (p. 34); es la omnipresencia de la poesía en el mundo y de éste en aquélla. Podría decirse incluso que el mundo "es", existe, poéticamente gracias al poeta, al poema y a la poesía que permea el universo sin dejar libre ningún intersticio. El lenguaje se hace sustancia del mundo material y le da sustancia inclusive más allá de la temporalidad fugaz de toda materia.

Siguiendo, pues, lo propuesto por Lezama en su sistema poético, éste comienza en su propia vida, y para conocer su universo literario "debemos conocer su universo cotidiano" ${ }^{\text {n3 }}$. Es aquí, en este diario existir, donde nace toda semilla literaria que posteriormente dará frutos poéticos; los elementos propios de la poesía son el poema y el poeta -además de lo formal como la imagen y la metáfora--. La vida es, pues, inseparable del producto de esa vida.

Ahora bien, a pesar de su canto de triunfo ante la muerte, Lezama no es ajeno a la problemática existencial. La poesía también transcurre en el ámbito de lo maravilloso y del portento; de lo desconocido que por ser tal no deja de producirnos angustia. Creer que se puede vencer a la muerte es después de todo una locura, sana, pero locura al fin; de allí las dudas, las crisis de esa fe: el horror vacui que nos asalta imprevisiblemente. Por eso Lezama inscribe en el umbral de su sistema poético varias sentencias, todas ellas al usivas al problema de la fe; desde el Caritas amnia credit de San Pablo hasta el "lo máximo se entiende incomprensiblemente", de Nicolás de Cusa.

\section{POESIA Y PROSA}

La unidad que Lezama percibe en su obra es tal que las fronteras entre su poesía y su prosa sólo serían mera forma exterior, porque la estructura profunda de ambas es la misma; ha dicho Lezama: "Yo no creo que los que estaban acostumbrados a mi poesía tengan una gran sorpresa al pasar a la novela (habla de Paradiso), todo es uno y lo mismo, y como ya decía Goethe, 'un pedazo de la naranja tiene el sabor de toda la naranja"' (p. 21)4.

Tanta es la importancia de la prosa lezamiana para entender su poesía, y en concreto, tan esencial es conocer Paradiso, que el propio Lezama se encargó

\footnotetext{
3 Armando Alvarez Bravo, "Orbita de Lezama Lima",op. cil., 44.

4 Idem, 42.
} 
de remarcarlo: "Creo que Paradiso permitirá al fin una penetración más justa de mis obras anteriores" (p. 25); concibiéndola como una suerte de suma de su trabajo poético y una clave para ingresar a éste. Paradiso, y su prosa en general, es lo diáfano, lo de luminosidad meridiana, comparado con la poesía que Lezama consideraba su lado oscuro; oscuro en relación a su prosa, porque en otro momento Lezama declaró que no pensaba que su poesía fuera más difícil que cualquier otra, concebida ésta siempre no sólo como obra publicada, sino como parte de un complejo sistema poema-poesia-poeta. Lo que postula Lezama es la estrecha unidad del corpus total de su obra, en la cual los distintos géneros cultivados por él no serían sino ángulos distintos de una sola y única realidad hipostasiada.

En su "Introducción a un sistema poético", Lezama parte de la verificación del "existir" como "ser en imagen", puesto que Dios creó al hombre a imagen suya; por lo tanto, concluye, existimos como fragmento del Absoluto, y fragmento que lo refleja, si no en el detalle, sí en las líneas esenciales. El SER es el Absoluto, Dios; el EXISTIR caracteriza al hombre, a lo transitorio. La antinomia "el existir. del ser y el ser del existir" encuentra en la poesía, y sólo en ella, la forma de mantener lo imposible de la síntesis. En la poesia, el mundo extensivo, "súbito", y el ser, son incorporados por el discurso poético en reciprocidad de sentencias y de imágenes; la identidad de ese discurso poético se alcanza en el instante mismo en que se transubstancian lo antinómico del ser y del existir, en una marcha de lo irreal a lo real. Se aíslan las significaciones, se destruyen, se disgregan, y se reconstruyen al final prisioneras del sentido, pasando "de remolino a estado", "de reflejo a permanencia".

La imago poetica se sitúa en las profundidades plutonianas, de allí que haya que descender hacia ella; es el órfico adentrarse en el reino de lo oscuro, de la muerte, para obtener alli la vida -Euridice- en las imágenes poéticas. El poeta, pues, desciende; la imagen poética asciende en la voz del poeta y desciende luego sobre el mundo, unificando en ella todos los contrarios imaginables, incluyendo la unión más imposible: la de la vida y la de la muerte; de allí el carácter de la imagen poética de esencia alquitarada de antinomias.

Esta concepción funcionaria, según el propio Lezama, de la siguiente manera: "toda realidad de raíz poética o teocéntrica ... engendra una reacción de irrealidad ... que a su vez en toda realidad que allí participe ... adquiere una gravitación, engendrando el cono de sombra donde la imago desciende" (p. 20).

Aplicando esto, por ejemplo, al verso primero de $M$ uerte de Narciso, "Dánae teje el tiempo dorado por el Nilo", diríamos que Dánae sería la "realidad de raíz poética o teocéntrica"; que el "tejer el tiempo dorado" sería la reacción de irrealidad; "por el Nilo" vendría a ser la realidad que allí participa y en la cual el "tejer" adquiere su gravitación engendrando el halo pcético — cono de sombra"- sobre el que se asienta la imagen.

'Algunos tralados en La Habana (Barcelona: Editorial Anagrama, 1971). 
Más adelante, en el mismo ensayo, enfatizando lo dicho, Lezama insiste aunque ya no a nivel del poema, sino de "la región de la poesía" - en que en la poesia "éste es aquél" en un infinito mundo de contrastes y uniones que dan origen a las metáforas. La poesía, a través de esa esencia, se constituye en instrumento para hurgar en la realidad, en esa realidad transreal que es el "ser universal", que está en la realidad pero también la trasciende.

Hablando de la persona del poeta, Lezama rescata de la Poética aristotélica la idea de que "el arte de la poesía es propio o de naturales bien nacidos o de posesos". Los poetas buscan -la poesía también-la inmortalidad, el "risueño desconocido de los dioses". No llaman la atención estas acotaciones acerca del poeta si se toma en cuenta la concepción transubstanciada de poesía-poetapoema a la que nos hemos referido al inicio de este ensayo.

Después de todo esto, cobra sentido la definición lezamiana de la poesía como "ente de razón fundado en lo irreal"s, dicho por él también de otra manera: "¿la poesia? Un caracol nocturno en un rectángulo de agua".

\section{POESIA Y EXEGESIS}

Con esta definición de la poesía, Lezama nos hace ingresar en el mundo de Io portentoso, porque todo lo que nos propone en su poesia, su prosa de ficción y sus ensayos, pertenece al reino del prodigio; y Lezama lo hace con tal estilo que de él puede decirse lo que él sostuvo de Santo Tomás, que "la gracia de la abundancia justa le fue concedida a su discurso".

Retomando el verso primero de Muerte de Narciso, quisiera ahora referirme a algunos aspectos de lo que significa la exégesis lezamiana. Una sensación de desaliento puede ser muchas veces lo primero en ocurrir al lector novato de Lezama, pues ante su denso y pletórico discurso no puede sino reconocerse la jluminación especial de que gozó Lezama, y comprobar que sólo una constante y paciente lectura de sus textos nos descubrirá sus profundidades. El mismo Lezama hizo alguna vez el distingo entre escritores complejos y escritores complicados; pues bien, de él puede decirse que no es complejo sino complicado, es decir, que se entrega "a las insinuaciones de la serpiente", y sus significados se dan al lector sólo después de repetidas lecturas".

En el caso de la poesía de Lezama, tal vez tenga razón Octavio Paz cuando dice "nada más huidizo e indefinible que lo poético"10. Pero es innegable, y es lo primero que se comprueba, que existe un halo poético que nos envuelve apenas pronunciamos algunos versos de Lezama; sabemos inmediatamente que esta-

\footnotetext{
6 "Playas del árbol": Algunos ..., 116.

${ }^{7}$ Idem: 118.

\& "Plegaria tomista": Algunos tratados en La Habana (Editorial Anagrama, 1971), 58.

- "Complejo y complicado", Algunos 49-50.

${ }^{10}$ El arco y la lira (México: FCE, 1956) 11.
} 
mos frente a una escritura que no podemos calificar sino de poética; y ante este punto de partida acaso debemos decir - parafraseando a Dante_ “dejad toda explicación los que aquí entráis”.

Es verdad que acaso no tenga ningún sentido preguntarse por el significado de Muerte de Narciso. Este poema es, en primer término, un atentado contra la lógica; no debemos buscar en él una concatenación coherente de ideas; tal vez no debamos buscar esto en ninguna poesía, pero en la de Lezama menos que en la de nadie. Aquí el poeta no "quiere decir", solamente "dice", y por eso el desciframiento textual de cada verso y estrofa sea tal vez una tarea inútil. Muerte de Narciso puede tan sólo atribuirse a un tema o a varios temas más o menos genéricos.

La actitud ante la poesía de Lezama creo que debe ser la de entregarse a ella, tal como lo proponen los críticos origenistas ${ }^{11}$. Pero entrega no quiere decir rendimiento incondicional; es sí un reconocimiento de que se está frente a palabras mayores, pero humanas al fin y al cabo y, por lo tanto, descifrables en alguna medida. La exégesis lezamiana se torna así una suerte de iluminación, de revelación que sólo es concedida después de una constante lectura, repetición en al ta voz y meditación de los versos ${ }^{12}$.

Desde el título, Muerte de Narciso, se anuncia con exactitud el tema que se va a tratar; y en verdad lo que hace el poema es hablar sobre la muerte de Narciso; se describe minuciosamente el contexto mítico y el ambiente físico en el que la muerte ocurre; por momentos parece el lector estar escuchando la descripción de una pintura sobre el tema.

Muchos son los elementos evocados por el poema. El más general de ellos es la figura misma de Narciso, que sugiere como tema global el de la poesía como contemplación de sí mismo y que conduce a la muerte que, como hemos visto, es vencida por el hecho mismo de la creación. En este sentido, el ser poeta conlleva aceptar la muerte, si, pero también la derrota de ésta como consecuencia del ejercicio de la poesía. Este auto-contemplarse implica que uno mismo es el centro de la creación en tanto ser creado a imagen y semejanza del Creador Supremo, y, por lo tanto, el misterio de la existencia reside en cada ser humano, y para penetrar dicho misterio no hay sino que mirar en su interior. Ese sería el sentido de Muerte de Narciso, y de allí que sea el que sirva de pórtico a la creación lezamiana.

Se trata no de una "disolución del Yo" ${ }^{13}$, sino de una concentración superlativa en el Yo, y a través de ésta una apertura hacia el misterio del ser y del existir.

"Arnaldo Cruz, "Entre la metáfora y la imagen: La crítica lezarriana", La crílica literaria en Latinoamérica, ponencias del XXIV Congreso del Instituto de Literatura Theroamericana, Stanford University $8-12$ de julio de 1985. (Lima: edición a cargo de Esteban Quiroz Cisneros, 1987)。

${ }^{12}$ Guillermo Sucre, "Lezama Lima: el logos de la imaginación", La máscara, la transparencia (Caracas: Monte Avila Editores, 1975).

${ }^{13}$ Ibidem, 193. 
No se trata de un mirarse y enamorarse de sí mismo, tal como lo propone el mito; porque en el poema, al parecer, Narciso no llega a ver su rostro, y por lo tanto no habría enamoramiento ni tampoco muerte por el afán patológico de la posesión; Narciso no muere, sino que es muerto, equiparándosele a un ciervo acosado y asesinado; los versos medidos del principio y los versos más bien sin límite de las estrofas posteriores, corresponderían al crescendo ascendente y al clímax del acoso y la cacería.

Esto da pie para comprobar otra característica del poema, que es la de la subversión del mito, la cual encuentra su correlato textual en la subversión de la sintaxis, en los verbos sin sujeto definido, en la superposición de significados, en la presencia de pronombres sin antecedentes claramente discernibles, etc.

El primer verso y la primera palabra de éste nos enfrentan a lo mítico: Dánae, hija de Acriso, encerrada por su padre en una torre de bronce, a la que Zeus sedujo ingresando en forma de lluvia de oro; fruto de esta unión fue Perseo. Dánae y su hijo fueron puestos en un cofre por su padre y echados al mar; fueron recogidos por un pescador, quien los entregó a Polidectes, rey de la isla Seriphus, quien los acogió.

El verso primero, al aludir a Dánae alude también a Perseo. Este no podía ver de frente a Medusa sin riesgo de morir; lo hace a través del escudo que le proporcionó Minerva. Narciso muere por contemplar su belleza directamente.

Aracne, la hábil tejedora, lanzó a Minerva un desafío para definir quien tejía mejor. En su tejido Aracne representó los errores de los dioses, entre ellos la seducción de Dánae por Zeus. La subversión del mito continúa; ya no son las Parcas las que tejen el hilo de la vida -el tiempo-; Lezama hace que sea Dánae a través de Aracne - la retadora de los dioses-, y Dánae es, después de todo, una vencedora gracias al triunfo de su hijo Perseo.

El mito marca, pues, como ha sido ya tantas veces señalado, el ingreso al tiempo fabuloso, pero también es la entrada en el no tiempo, es decir en aquella zona en la cual ya no interesa el paso de los días, lo contingente. En el verso primero de Muerte de Narciso los mitos se entrecruzan y complementan hasta crear nueva mitología: Dánae - a través de Aracne-_ “teje”, es decir da vida dentro de sí al "tiempo dorado", es decir, a Perseo, el vencedor, engendrado por la lluvia de oro de Zeus. Cobra así sentido para el lector ese primer y famoso verso: "Dánae teje el tiempo dorado por el Nilo".

La mención al Nilo nos remite al mito de Osiris, rey de los muertos identificado segưn algunos egiptólogos con el río Nilo, en una misteriosa y ambigua alusión a quien siendo dios de los muertos y careciendo de órgano viril, engendró a Horus, dios de la vida. De modoque el "tiempo dorado" es sí la lluvia de oro de Zeus, pero ese tiempo es también "dorado por el Nilo", es decir, por Osiris.

El juego de las transmutaciones es constante. Esta mención al Nilo se explica también en las propias palabras de Lezama al hablar de las "metamorfosis ácueas" como tradición en la poesía española; así, dice, "El dios que llega 
(en este caso Zeus-Osiris) lo mismo puede ser saludado como un familiar que como un río ${ }^{\eta_{14}}$. Con el primer verso de Muerte de Narciso Lezama no sólo consigue una coherente transmutación de mitos diferentes, sino que además, Io hace dentro de la tradición poética española, y, sobre todo, consiguiendo como resultado uno de los versos más bellos de la poesía de nuestro siglo.

El poeta seria el que contempla la vida a través de sí mismo - Narciso-y muere por ello; pero también el que contempla lo terrible a través del espejo de su poesía y vence - Perseo-; sin que olvidemos que en el mito Medusa fue una joven hermosa y de cabellos que eran su gloria, y que Minerva convirtió en serpiente por haber osado compararse a ella. De ese modo lo terrible y lo bello se funden de la manera en la que Rilke habló de la belleza como el grado de lo terrible que los humanos podemos soportar.

La poesia sería el estanque en que Narciso se contempla, y también el escudo de Minerva a través del cual Perseo contempla a Medusa y triunfa sobre ella.

. 14 "Sierpe de don Luis de Góngora", Analecta del reloj, Obras complelas, vol. 2 (Madrid: Aguilar, 1977) 203. 